\title{
Black Mirror Dizisinde Nöro-İmge ve Beyin Ekranlar
}

\author{
Ömür Şölen Soykan*
}

\section{$\ddot{O} z e t$}

Nöro imge Patricia Pisters'ın Berlin Duvarı'nın yıkılışı ve 9/11'in politik olarak zeminlediği nörobilimsel ve bilişimsel değişimlerin hazırladığı yeni bir sinematografik imgeyi tanımlayıp açıklamak için Deleuze'ün sinematografik yaklaşımı doğrultusunda ürettiği, hareket imge ve zaman imgeyi takip eden bir kavramdır. Zamanın üçüncü sentezine, gelecek zamana ait olan nöro imge nörobilimsel gelişmeler ve çevrimiçi kültürel gelişmelerle paralel ortaya çıkmıştır. Geleceğin önalımsal tasarlanmasının politik etkisi altında gelecek zamanda sentezlenen sinematografik imgedir. 21. yy. sinemasında nörobilimsel ve çeorimsel gelişmelerin yol açtığı temalarn bir arada kullanılmasıyla karakterlerin gözünden değil, zihninin içinden, beyin ekranlar aracilığıyla izlediğimiz bir sinematografi ortaya çıkmıştır. Patricia Pisters bu yeni sinematografik ögeyi Deleuze-Guattarici şizoanaliz çerçevesinde ele alarak nöro imge diye kavramsallaştırmış, "beyin ekrandır", beyin ekranlar çerçevesinde incelemiştir. Bu çalışmada nöro-imgeyi bilim alanına tanıtmak amacıyla Netflix, Black Mirror dizisinde zamanın üçüncü sentezinde yer alan nöro imge, beyin ekranlar ve onlara eşlik eden zihin mimarileri bulgulanıp açıklanmıştır. Bu amaç doğrultusunda şizoanaliz yöntem olarak kullanılmıştır.

Anahtar Kelimeler: Nöro İmge, Black Mirror, Beyin Ekran

*ORCID: 0000-0003-4455-5545

E-Mail: omursoykan@hotmail.com

DOI: 10.31122/sinefilozofi.660791

Geliş Tarihi - Recieved: 05.01.2020

Kabul Tarihi - Accepted: 31.04.2020 


\title{
Neuro-Image And Brain Screens İn Black Mirror Tv Series
}

\author{
Ömür Şölen Soykan*
}

\begin{abstract}
Neuro-image is a concept follows movement-image and time-image, generated by Patricia Pisters through Deleuze cinematography in the aim of characterize and clarify the new cinematographic image which has been assemblaged by neuroscientific and cognitive progresses based on the political occasion of demolition of Berlin Wall and 9/11. It belongs to third synthesis of time, future and formed in parallel neuroscienetifical and online internet cultural develepments. It's a cinematographic image is synthesized at the 3th synthesis under the political effect of pre-emptive design of future. The cinematography appeared in 21th century cinema that we see world within characters minds, not through eyes is assemblaged by themes which are given a lead by online and neuroscientific progresses. Patricia Pisters approached this new cinematographic component in the frame of Deleuze-Guattari schizoanalysis, researched in the frame of "brain is screen", brainscreens and conceptualized. In this paper, neuro-image at the 3th synthesis of time, brain screens and cognitive architectures in Black Mirror serial, Netflix, detected and explained in the aim of introducing neuro-image concept to Turkey cinema field and schizoanalysis utilized as a practice.
\end{abstract}

Key Words: Neuro-Image, Brain Screens, Black Mirror Tv Series

*ORCID: 0000-0003-4455-5545

E-Mail: omursoykan@hotmail.com

DOI: $10.31122 /$ sinefilozofi. 660791

Received - Geliş Tarihi: 05.01.2020

Accepted - Kabul Tarihi: 31.04.2020 


\section{Giriş}

"Çünkü hafıza yaşamak içindir"

(Black Mirror; Rachel, Jack ve Ashley

Too, Brooker, 2019).

Sinema birçok sanat alanını kuşatan çağdaş zenginliği ve kökenlerinden gelen kendine özgü büyüsüyle dün olduğu gibi bugün de hem insan öznelliğine hem de kolektif olgulara 1şık tutuyor, onlarla beraber gelişiyor. Bu nedenle sinema felsefe ilişkisi gün geçtikçe daha fazla önem kazanıyor. Çağdaş düşünürlerin çoğu sinemayı görüşlerini açıklamak için kullanmıştır. Deleuze ise bir sinematografi yaklaşımı geliştirmiş olması nedeniyle sinema için daha önemli bir konuma yerleşmiştir. Zaman ve sinema arasındaki doğrudan bağ1 çözüp ortaya koyan Deleuze sinematografisi yarım asırdır sinema alanında çalışma yapanların en değerli felsefi yaklaşımlarından biri, açıkçası en önemlisidir.

Deleuze (2013, 2014) hareket-imge ve zaman-imge kavramlarını kurarak sinema anlayışımıza büyük bir katkı yapmıştır. Hollandalı akademisyen Patricia Pisters (2012) ise bu kavramlara Nöro-imge: Dijital Ekran Kültürü’nün Delözyen Film Felsefesi adlı kitabiyla nöroimge kavramını eklemiştir. Nöro-imge zamanın üçüncü sentezindeki imge türüdür.

Pisters adı koyulmamış örnekleri 20. yy sineması zaman-imgesinde gömülü olmakla beraber, 21. yy sinemasında ortaya çıkan yeni bir sinematografik imgeyi tanımlayan nöroimge kavramını nörofelsefe zemininde üretirken Deleuze felsefesinden çalışmanın genelinde yararlanmış, şizofreninin süreçsel ve patolojik boyutlarını değerlendirmenin yanı sıra, Deleuze-Guattari'nin (2014) AntiÖdip çalışmasında psikanalize alternatif olarak ortaya koyduğu şizoanalizi yöntem olarak kullanmıştır (nöro-imgenin teknomateryalist ve etikestetik yönlerine bakarak). Veri tabanları ve software'lere dayalı dijital kültürden nöroimgenin üçüncü sentezle ilişkisini açıklamakta yararlanmıştır (zamanın birinci sentezi motor-hafıza, ikinci sentezi bellek gibi çalışır, üçüncü sentez yani nöro-imge ise veri tabanı mantı̆̆ıyla çalışır). Nöroloji alanındaki yeni çalışmaları ise beynin ekran olduğunu ve ekranların beyin gibi işlem yaptığını açıklamanın yanı sıra, nöro-imge'yle psikozlar arasındaki ilişkiyi sergilemek izleğinde ele almıştır (beyin görüntüleme teknikleri, patoloji olarak şizofreni, sinapsisler, nöroplastiti, sağ beyin - sol beyin ilişkisi vs).

Pisters, Deleuze'ün (1998:49) sinema, beyin ve hareket arasındaki ilişkiyi açıklamak için bir röportajında söylediği aşağıdaki ifadeden yola çıkarak beyin ekran kavramına varmış ve nöro-imgeyi üretirken izlediği kavramsallaştırmanın zeminine yerleştirmiştir. Deleuze'ün yaklaşımına göre beyin ekrandır ve ekran beynin prensipleriyle işlem görür.

"Beyin ekrandır... Sinema, imgelere hareket verdiği dahası onlara içsel hareket bahşettiği için beyin devrelerinin izini sürmeyi asla bırakmaz".

$\mathrm{Bu}$ çalışmanın amacı Türkiye için yeni bir kavram olan nöro-imge kavramını bilim alanına tanıtmaktır. Bu amaçla seçilen Black Mirror dizisindeki beyin ekranlar aracılığıyla nöro-imge serimlenmiş ve çalışma sırasında bulgulanan zihin mimarileri (cognitive 
architectures) ${ }^{1}$ değerlendirilmiştir. Black Mirror dizisi (Charlie Brooker, 2011-günümüz) Birleşik Krallık bilim kurgu dizisidir. Hollywood bilim kurgusundan farklı kendine özgü yönleri olan distopik bir dizidir. Her bölümü birbirinden bağımsızdır. Amaç gereği içerik kapsamı geniş tutulmuş ve ilk bölümünden bildiri tarihine kadar olan tüm bölümler ele alınmıştır, benzer bir çalışmada tek bir bölüm derinlemesine incelenebilir.

Pisters sinematografik nöro-imgenin gelişiminde politik sinemaya önemli bir yer vermiş ve birçok politik filmi incelemiştir. İncelediği filmlerde ortaya koyduğu önemli bir özellik filmlerin şizoanalitik, nomadik karakteristiği, sanal-edimsel devresinin işleyişidir. Nomadik strateji yeni bir zamanı, geleceğin zamanını yaratmaktadır. Black Mirror dizisinde de bu tür nomadik stratejiler dizinin anlatısını oluşturmakta, dizi ontolojisi bu stratejiler aracılığıyla gelecek zamanı kurmaktadır. Diziyi Hollywood bilimkurgusundan ayıran en önemli özellik budur. Distopya başlı başına bir nomadik stratejidir, yanı sıra beyin alanındaki yeni bulguların ve nörobilimin dijital kültürle iç içe geliştirdiği ve henüz geliştirmediği hayal edilebilir teknolojilerin bir arada işlenme biçimi, görünmeyenin makinesel rejiminin görünenin makinesel rejiminin yerini alışı dizinin ürettiği diğer nomadik stratejilerdir. Bunlar zihin mimarilerine yön verdikleri için Beyin ekranlar ve Zihin Mimarileri bölümünde daha ayrıntılı olarak aktarılmıştır. Her bir bölümde çekim teknikleriyle oluşturulan nomadik stratejiler de vardır ve Metal Kafa (Metal Head, 2017) bölümündeki çekim tekniği ve savaş kameraları izlenimi veren Lidar kamera-tarama ve $2 \mathrm{~d}$ tekniği buna verilebilecek bir örnektir.

Şizoanaliz amaca uygun olarak kullanılmış ve nöro-imge bağlamında beyin ekranlar ve zihin mimarilerinin tekno-materyalist ve etik-estetik yönleri bir arada değerlendirilmiştir.

Alg1 Lojistikleri 2.0 başlıklı bölümde nöro-imgenin ortaya çıktığ1 tarihsel koşullar ve ortam açıklanmış, incelenen materyaldeki beyin ekranlarla ilişkisi gösterilmiştir. Ayrıca Pisters'ın ara uğrağı zihin mimarileri kavramı bir kilit olarak çerçevedeki yerine yerleştirilmiştir. Şizoanaliz bölümünde şizofreninin süreç ve patoloji olarak Deleuze felsefesindeki yeri belirtilmiş, özellikle patolojik şizofreninin nöro-imgeyle ilişkisine yer verilmiştir. Zaman Sentezleri bölümünde nöro-imgenin zamanın üçüncü sentezinde yer alışını açıklamak amacıyla, Bergson ve Nietzsche'den yola çıkan Deleuze'ün zaman sentezleri yaklaşımı açıklanmış, Pisters'ın nöro-imgeyi üçüncü sentezde bulgulayışı çözümlenmiştir. Beyin Ekranlar ve Zihin Mimarileri bölümünde daha önceki bölümlerde yapılan açıklamalar ışığında Black Mirror dizisindeki zihin mimarileri ortaya koyulmuştur. Sonuç bölümünde bulgular değerlendirilmiştir.

\section{Alg1 Lojistikleri 2.0}

Deleuze zaman-imge' nin ortaya çıktığı tarihsel koşulları ele alırken birçok olayın eşzamanlı bir aradalığını, bir olaylar demetini (assemblages) vurgulamıştır. Pisters bunu temel alarak nöro-imgenin ortaya çıtı̆̆ tarihsel zemine dijital alandaki gelişmeler, internetin ortaya çıkışı, beyin görüntüleme tekniklerini takip eden bilişsel nörolojideki

\footnotetext{
1 Bkz: Hauptmann, D., \& Neidich, W. (2010). Cognitive Architecture: From Bio-Politics to Noo-Politics;
} Architecture \& Mind Inthe Age of Communication and Information. 
gelişmeler gibi birçok gelişmeyi yerleştirmiştir. Politik düzlemde ise iki olayın öne çıktığını ifade etmektedir. Bu olaylar Berlin Duvarı'nın ve İkiz Kuleler'in yıkılmasıdır (9/11). İlk olayda dünyayı ikiye bölen politik yarık komünizm-kapitalizm çelişkisinden, en azından görünüşte, sıyrılmış, yeni bir yön kazanmıştır. İkinci olayda bu yön belirginleşmiştir. İki olayın arasında ise Körfez Savaşı'nın birinci evresi vardır. Pisters algılarla savaş arasında, mimari uğrağından da geçerek, doğrudan bir ilişki kuran Virilio'nun (1989) Algı Lojistikleri 1.0 kavramını geliştirmiş, çağımızın nöropolitiğini değerlendirirken Alg1 Lojistikleri 2.0 kavramını üretmiştir.

Alg1 Lojistikleri savaşları algılayışımızla doğrudan ilgilidir. 1. ve 2. Dünya Savaşları sırasında savaşı algılayışımız bugünkünden farklıydı. Vietnam savaşında savaş ortamından gelen görüntülerin ve haberlerin kamuoyunu yoğun biçimde etkilemesi nedeniyle ABD alg1 lojistiklerini kontrol edebilmek amaciyla Baudrillard'ın (1995) olmayan savaş (nonwar) diye nitelediği simülasyon alg1 lojistikleri geliştirmiştir. Virilio'nun Alg1 Lojistikleri 1.0 kavramsallaştırması bu lojistikleri işaret etmektedir. Özellikle Web 2.0'1n gelişmesiyle durum değişmiştir. Dünyanın her yerinden imgeler, metinler internete akmakta, savaş bölgelerinden de en ayrıntılı görüntüler gelmektedir. Savaşın en çarpıcı görüntüleri günlük hayatın bir parçası olmuştur. Sonuç olarak insanlar adrenalin peşinde savaş görüntüleri izler hale gelmiş, video savaş oyunlarının da etkisiyle savaş-oyun arasındaki fark flulaşmıştır. Web 2.0'nin etkileşimi konunun önüne geçiren karakteristiği savaşın bir sorun olmasının önüne internete yağan savaş görüntülerini ve o görüntülere yapılan yorumları taşımıştır. İmge silaha silah imgeye, oyun savaşa savaş oyuna dönüşmüştür. Tüm bunlara eşlik eden teknomateryalist öge ise bu savaş-oyunlarının bağımlılık yapan adrenalin üretimi, toksik üreten nörothrills yönü ve şizoanaliz bölümünde açıklanacak dijital kültür, beyin işlevleri ve psikoz arasındaki ilişkidir.

Öte yandan Cezayir Savaşı (La battaglia di Algeri, Pontecorvo, 1966) filmi hem tüm dünyada politik sinemayı ve hem de gerilla hareketlerini etkilemiş, neredeyse bütün gerilla grupları bu filmdeki taktikleri taklit etmiştir. Pentagon düşmanının her yerde, duvarların içinde, kadınların sepetlerinde olduğu bu filmde anlatılan taktiklere karşı taktikler geliştirmiştir. 2003'te filmin Pentagon'da ekrana verildiği resmilik kazanmıştır. 2004'te film yeniden gösterime sokulmuş, bu gösterim için fragmanı değiştirilmiştir. Fragman ilk fragmandaki görüntülerin yeniden kurgulanmasıyla oluşturulmuştur. Pisters bunu önemli bir gelişme olarak kaydetmektedir.

Veri tabanı mantığını açıklamak için verdiği en dikkat çekici örnek Redacted (Palma, 2007) filmidir. ABD askerlerinin savaş bölgesinde bazı kadınlara tecavüz ettiği ortaya çıkınca Palma bu konunun filmini yapmaya karar verir. İnternette yaptığı araştırma sonucunda tahmin ettiğinden çok daha fazla materyalle karşılaşır. Askerlerin savaş günlüğü videoları bile vardır. Tüm malzemeyi kullanması için bunları bir veri tabanı mantığıyla bir araya getirmesi gerekmektedir. Bunu daha iyi açıklamak için Black Mirror dizisindeki Beyaz Ayı (White Bear, 2013) bölümünü hatırlayabiliriz. Kadın sabah uyandığında karşılaştığı görüntüleri zihninde bir araya getirmek durumundadır. Yere saçılmış ilaçlar, beyaz bir ayı, kendisine sarılmış bir adamın resmi ve o resmin yanında bir çocuk resmi. Aralarında yapısal bir ilişki olmayan bu görüntülere daha sonra sokakta karşılaştığı olaylar eklenir. Zihninin bir 
veri tabanını işler gibi işlem yapması gerekmektedir. Bu veri mantığı farklı şekillerde ortaya çımmaktadır. Zihinler gayrişahsi bir hipertekst gibi işlemektedir; imgelerin, verilerin, metinlerin, ses ve görüntülerin aralarında yapısal bir ilişki olmadan biriktirildiği birer koleksiyona dönüşmüştür. Ve bu tam da Manovich'in (2011) dijital kültürü açıklamakta kullandığ 1 ifadedir.

Alg1 stratejileri 2.0 dijital kültürün ve çağdaş minör politik mücadelelerin, üretim ve karşı üretim stratejilerinin ve çoklukların değişik boyutlarını barındırır. Pisters' ın $(2012,298)$ ifadesiyle "etkili bir dolaşıklığa yol açan belirli bakış açılarının ve psikolojik etkilerin devasa barok perspektifler ağ"ıdır. Web 2.0 temelli, etkileşimli medyanın baskın üretimi, çoklu ekranlar, ekranın her yerdeliği (omnipresence), Teknodelirium, video oyunu estetiği, adrenalin üreten savaş-oyun yakınsaklığı, yakınsak medya ve savaş günlükleri estetiği, korku filmi estetiği, toksik üreten nörothrills, silahların efekt, efektlerin silah olarak kullanımı, düşmanın ve röntgencinin her yerdeliği, el kameraları, öznel ve kaotikçe yoğun imgeler, efektler ve bunları kuşatan gayrişahsi hipertekstler, Delirium Sineması, simülasyonlar, beyin beden ilişkisi, şizo ekranlar, şizo beyinler, Bedenlenmiş Gösteri'nin ulusötesi ve antidüalist krizi², minör "oluş" sinematografisi, algoritmalar, veri tabanları, veri madenciliği, imgenin ileri geri sarılabilmesi ve remikslenebilmesi, dijital şiirsellik, beyin görüntüleme teknikleri ve bu tekniklerin dijital kültürle ilişkisi gibi birçok özellik Pisters'ın nöro-imge kavramını kurarken uğradığı Alg1 Lojistikleri 2.0 özelliğidir ve Black Mirror dizisi bu özelliklerin tümünü barındırmaktadır.

Bandersnatch (2018) bölümüne baktığımızda web 2.0'ın bir özelliği olarak etkileşimin sinematografik kurguya doğrudan temasıyla karşılaşıyoruz. Farklı algoritmik sorun çözme mekanizmalarını kullanan katılımcıların vardığı yer ise, mesela socius'un sınırındaki şizonun uzattığı ilacı içseler de içmeseler de değişmiyor. Cinnet. Beyin görüntüleme teknolojisinin uyarlanmasıyla zihindeki görüntülerin onları simüle eden ekranlar aracılığıyla izlenebildiği başka bölümlerde de sonuç ayn: Senin Tüm Geçmişin (The Entire History of You, 2011), Arttırılmış Gerçeklik (Playtest, 2016), Arkangel (2017). Bazı bölümlerde ise kitlesel cinnetle karşılaşıyoruz: Sosyal Linç (Hated in The Nation, 2016), Ulusal Marş (National Anthem, 2011), Beyaz Ayı (White Bear, 2013) Bunun dışında birçok bölümde dijital kültürle etkileşim ve suç içiçe, üstelik bu suçların ortak özelliği Netflix'in Black Mirror dizisi tanıtımında ifade ettiği karanlık içgüdüler. Cinnet geçirerek kendimize ya da başkasına zarar vermeden yaşamanın tek yolu varmış gibi görünüyor. Onbeş Milyon Hak (Fifteen Million Merits, 2013) bölümünde kararkterler ekranlardan oluşan izole bir arafta yaşamaktadır. İzole bir arafta yaşamak, bu bölümdeki gibi bir fırsat kollamak ve belki de onu da bir anda yeniden içgüdülerimiz nedeniyle kaybetmek. Black Museum bölümünde olduğu gibi doğrudan başkasının beyninin içinde yaşamak, dünyayı onun beyin ekranı aracılığıyla görmek mümkün olsa bile karanlık içgüdüler peşimizi bırakmaz.

\footnotetext{
$2 \mathrm{Bu}$ makropolitik ögeyi en iyi açıklayan ifade ABD Savunma Bakanlığı'nın sponsörlüğünde enformasyon üstünde tam kontrol sağlamak amacıyla 1998 yılında noopolitik stratejiyi yapılandıran Ronfeldt, Arquilla'nın (2018) The Continuing Promise of the Noösphere and Noöpolitik: Twenty Years After adlı yayınında yer almaktadır."... en etkili uygulayıcılar sofistike medya teknolojileriyle donanmış ve küresel ağlarda organize olmuş militan cihatçılar oldu".
} 
İlk bakışta, işin aslı şimdiki zamanın perspektifinden bakınca, bütün bunlar teknolojinin ürettiği sorunlarmış gibi görünse bile aslında insanın çağlardır sorunsallaştırılmış hırsları, içgüdüleridir. Üstelik Rachel, Jack and Ashley Too (2019) bölümünde gösterildiği gibi insanın karanlık içgüdüleriyle hapsedilmişken insan tabanlı bir yapay zekanın yardımıyla özgürlüğe ulaşmak mümkün. Black Mirror dizisinde ve genelde 21. yy. sinemasında Delirium sinemasıyla bu kadar sık karşılaşmamızın nedeni ne? İnsan neden zihnin içinde olup bitenleri bu kadar merak ediyor? Beyin ekranlar, genel olarak dijital kültürle bunun ilişkisi ne? Konu burada gelecek mi? Derrida' nın (1996) ifadesiyle “ve geleceğin indirgenemez deneyimi olarak arşiv" mi?

Dijital kültür ve internet aracılığıyla dünyanın her yerinden gelen imgelerin, verilerin, metinlerin, ses ve görüntülerin biriktirildiği ve dağıtıldığı bu yakınsak çağa 1şık tutan önemli bir kavram Derrida'nın Açı Arşiv kavramıdır. Pisters sinemaya dünya hafızası olarak bakarken Açık Arşiv kavramını çağırmaktadır. Sürekli üretilen arşiv geçmişin kapatıldığı bir yer değildir, şimdiki zamana açıktır ve geleceği ummaktadır. Peki bu arşiv algılarımızı nasıl etkiler? Pisters bunu açıklarken Connolly'e (2002) başvurur. Bu uğrak Pisters'a iki çıkış sağlamıştır. İlk olarak:

“... Nöropolitik zihnin (bireysel ve kolektif zihnin) mikropolitikleriyle, makropolitik normlarla, ideolojilerle, kurumlarla ve stratejilerle ilişkilidir. Aynı anda birçok boyutu ve yönü tanımaktadır (sadece ideolojik olarak "doğru" olanı değil). Bu politik boyutlarıyla değerlendirdiğimizde nöroimgenin şizoanalizi hem yaratıcı yetkilendirmesini hem de tehlikeli boyutlarını gösterecektir" (Pisters, 2012:218).

Arşiv algılarımıza hem zihnin bireysel mikropolitikleriyle dolayısıyla beynin çalışma prensipleriyle, hem de kolektif zihnin mikropolitikleri ve bireysel zihnin bunları alımlama stratejileriyle, makropolitiklerden dolayımlanarak etki etmektedir. Nöro-imgenin son derece açık (openness) ve dinamik karakteri üretim ve karşı üretim stratejilerine, adaptasyonlarına, değerlendirmelerine ve bunların çeşitliliğine olanak sağlamakta, yol açmaktadır. Bu onun şizoanalitik karakteridir.

İkinci olarak Connolly'nin temel referansı Nietzsche'dir. Connolly'nin şimdiki zamanı “zaman aralığı" olarak değerlendiren yaklaşımı Nietzsche' nin ebedi dönüş kavramını nöroimgenin zamansal metafiziğine uygulamamızı sağlayan bir politik çerçeve vermektedir.

“Connoly'nin nöroekranların (beynimizdeki fark edilmez yer değiştirme ve değişimlerin) ve nörofelsefenin (zaman sentezleri kapsamında zamandaki aralıkların) nöropolitiklerle (küçük, büyük ve dünyatarihsel yer değiştirmeler) ilişkili olduğunu gösterdiğini öne sürmek mümkündür" (Pisters, 2012:219).

Bağıntısallığı daha iyi açıklamak için şizoanaliz ve zaman sentezleri kavramlarını gözden geçirmek gerekmektedir. Buna geçmeden önce açıklanması gereken bir ara uğrak vardır; Zihin mimarileri.

Pisters nöro-imgeye yön veren beyin dijital kültür ilişkisini, nöropolitikleri algılayışımızla beyin işlevleri arasındaki ilişkiyi göstermek için Neidich'in (2009) Neuropower makalesini çağırmaktadır. Burada eklenmesi gereken önemli bir nokta bilişsel nörobilimin 
beyinle yeni bulgular eşliğinde bedenlenmiş bir beyin yaklaşımına yönelmiş olduğudur. Neidich'in yaklaşımına göre beyin kültürel deneyimle şekillenmektedir. “Beynin potansiyeli" sadece nöronlar, nöral ağlar, sinaptikler sinaptik kimyasallar, vs ile değil aynı zamanda "salınımlar ve zamansal imzalarla" şekillenmektedir (123). Peki bunun nöro-imge açısından önemi nedir? Pisters o yöndeki düşünümünü açıklarken Neidich'in değindiği iki noktayı aktarmaktadır. Birincisi "aklın gözünün kurumsal şartlarıyla yarışmak için hassasiyetleri yeniden dağıtan" sanat ki nöro-imgenin sinematografik ortaya çıkışını buna dayandırabiliriz, ikincisi ise nörobilim dijital kültür ilişkisinin "Terörle Savaş" bahane edilerek toplumun davranışsalcı ve bilişsel denetimini sağlamak amacıyla istismar edilmesinin yaratabileceği olası sonuçlar. Pisters'ın sinematografik nöro-imgenin şizoanalizinde, genel olarak Delirium sinemasında bulguladığı zihin mimarileri psikoza, özellikle patolojik şizofreniye özgü Zamansal Mimarilerdir (Temporal Architecture). Beyin ekranlar ve zihin mimarileri kısmında Black Mirror dizisinde bunların ortaya çıkışını ortaya koyacağım.

\section{Şizoanaliz}

Deleuze ve Guattari'nin (2014) ortaya koyduğu yaklaşıma göre ilkel makinenin socius'u doğa da dahil olmak üzere socius'lar arzu makinelerinden oluşan birer arzu makinesidir. İnsan bu makinesel rejimin kullanıcısı değil bir parçasıdır, bitkilerin polenlerini bir yerden bir yere taşıyarak yeniden üretiminin parçası olan canlılar gibi. Bu makinesel rejimde arzunun rejimi çalıştırıcı bir rolü vardır, aktarım arzu aracılığıyla sağlanır. Arzu üretimi ve toplumsal üretim bir ve aynı şeydir. Temelde makinesel rejimle arzu arasındaki ilişki dolayımlıdır. Deleuze-Guattari'nin ifadesiyle "yaşamın kişisel ve özgül birliği bir kez azledildiğinde makine ile arzu arasındaki dolaysız bağ ortaya çıkar", makine arzulamaya başlar, arzu makineleşir. Hang the dj (2017) bölümünde yaşamın kişisel ve özgül birliği geri getirilebildiğinde arzunun makineleşmiş halinin dışına çıkmak mümkündür. Şizofreni bir süreç olarak hem üretim rejimine hem de karşı üretim rejimine içkindir. Black Museum (2017) bölümünde işlerin bir anda tersine dönmesi gibi. Süreçsel şizofreni ile kapitalizmin sakatladığı şizo, patolojik şizofreni aynı şey değildir ama şizo kapitalist makinenin tam sınırında durur. Waldo Zamanı (Waldo Moment, 2013) bölümünde olduğu gibi yaratıcı gücünü, sanatsal karşı üretimini kapitalin yeniden üretimi için kullandığ1 sürece rejimin içindedir, karşı üretimini rejimi değiştirmek için kullanmak istediğinde dışındadır. Psikozun sosyoekonomik ve dünya tarihsel oluşunun başka bir görünümü de belirli mal, hizmet ilişkilerine bağlı habituslarda özgürlük ve yaratıcılık olarak görülen psikozun daha dezavantajlı mal, hizmet ilişkilerine bağlı habituslarda hoşgörüyle karşılaşma şansının bile olmamasidır.

Freud'un yaklaşımına göre nevrozda gerçeklik bozulmamıs kalır, şizofrenide ise gerçekliğin yerini beynin içsel gerçekliği, illüzyonların, «görülmeyenin» gerçekliği alır. Deleuze çağdaş dünyayı anlamak için nevroz üstüne düşünmenin yetersiz olduğunu, her beynin potansiyel olarak şizofren olduğunu ve dijital kültürü (şizofren beyni) anlamak için şizofreni üstüne düşünmek gerektiğini vurgulamaktadır (zaman=beyin=ekran). Kapitalist makinenin merkezindeki psikanaliz ve ona eşlik eden temsil anlayışı başlangıç noktasından kaynaklanan içkin eksikliğiyle çözüm değil, ihtiyaç üretir hale gelmiştir. Deleuze ve Guattari 
şizoanalizi psikoanalize alternatif olarak üretirken şizoanalizin socius'la, psikanalizin aileyle ilişkisine vurgu yapmıştır.

Delirium her zaman sosyoekonomik ve dünyatarihseldir. Pisters bu vurgudan yola çıkarak patolojik şizofreninin nöro-imge sinemasındaki görünümlerini inceler ve nöroimgenin bu karakteristik özelliğini kavramsal düzleme taşır. Bunu yaparken Deleuze Guattari yaklaşımındaki aile belirleyici değil belirlenmiştir anlayışını geri çağırır. Patricia Pisters psikozun sosyoekonomik ve dünya tarihsel olması bağlaminda nöro-imgenin djital kültürle karşılaşma sonucu oluşan ve 21. yy. sinemasında sıklıkla işlenen deliliğin hem bir semptomu hem de panzehiri olduğunu öne sürmektedir. Nöro imge "(Şizo) akışına" uyar ve potansiyel olarak yeni bir şey yaratır, yaratıcı bir şey, bağlantı kurulacak yeni bir dünya» üretir. Bu kültürün parçası ve aynı zamanda bir direniş. Şizoanalizin süreçsel yönü üretim ve karşı üretim rejimleriyle ilişkilendirilerek birçok kez incelenmiştir, Pisters bunları göz ardı etmeden patolojik yönüne ağırlık vermektedir. Süreçsel yönünü ise şizoanaliz yöntemiyle harekete sokmaktadır. Guattari tarafından psikoanalize alternatif bir tedavi yöntemi olarak geliştirilen ve Deleuze iş birliğiyle felsefi içerikle buluşan şizoanalizin, şizofreninin üretim ve karşı üretim rejimlerine içsel olduğunu gösterebilen niteliği çok önemlidir. Bu nitelik bize patolojik şizofreninin teknomateryalist boyutlarını anlamanın Delirium sinemasının etikestetik boyutlarını anlamamıza yardımcı olabileceğini söylemektedir.

\section{Zaman Sentezleri}

Nöro-imgenin özelliklerini sıralamak gerekirse; şizoanalitik doğası, ekranların her yerdeliği (omnipresence), beyin ekran yakınsaklığı (beyin ekran) ve zamanın üçüncü sentezinde olması sayılabilir.

Zaman kavraminı süre (duration) olarak ele alan Bergson'un metafizik yaklaşımına göre «dirim, canlılık (life) en baştan, birbiri üstüne basamaklanan geçmiş, bugün ve gelecek sürelerinde bölünemez bir devamlılık formunda geçmişi korumak ve geleceği ummak, beklemekle görevlendirilmiştir» (Akt: Pisters, 2012, 132). Bu anlamdaki hafıza ve beklenti bilincin ta kendisidir.

Deleuze (2017), Bergson'un zaman kavrayışını Fark felsefesi için ele alırken içkinlik düzleminde yeniden kurar ve sinematografik yaklaşımına da temel olacak şekilde dönüştürür. İçkinlik düzleminde aktüel ve sanal arasında sadece edimsellikte bir ayrım vardır, gerçeklik bağlamında bu iki kavram birbirinin zıttı değildir, aksine aralarında kapalı bir değiş tokuş ve ara bağlantı vardır. Bergson'un zaman yaklaşımı sinemadaki zamanı anlayıp açıklamak için çok daha uygundur çünkü zaman=beyin=ekran. Deleuze bu yönde kavramsallaştırmasına Nietzsche'nin ebedi dönüş kavramını katar:

"Anın diğer anlarla ilişkisini kuran, onun kendisiyle şimdi, geçmiş ve gelecek olarak kurduğu sentetik ilişkidir. Ebedi dönüş bir sentez olarak düşünülmelidir. Ebedi dönüşte özdeşlik, geri dönenin doğasını değil, farklılaşanın geri dönme olgusunu ifade eder" (Deleuze, 2016:68).

Pisters, Resnais'in filmlerinden bazı örnekleri ele alırken dijital bir mantıkla karşılaşır: geçmişi bir araya getirmek, hatta çeşitli gelecekleri sunmak; görüntü ve nesnelerin, biyografilerin ve yaşların veri tabanı benzeri alternatiflerinin oluşturulması; ve hikayenin 
oluşumunu izleyicinin aklına devretmek. Başka filmlerde de rastladığı aralarında bir yapısal ilişki olmadan biriktirilmiş imgeler, metinler, verilerden oluşan zihinler, koleksiyona dönüşmüş zihinler onu Manovich'in dijital çağdaş kültür üstüne düşünürken ürettiği veri tabanı mantığı kavramına götürmüştür.

“Dünya bize sonsuz ve yapılandırılmamış bir imgeler, metinler ve diğer veri kayıtları gibi gözüküyor... Bu sadece onu bir veritabanı olarak modellemek üzere harekete geçeceksek uygun bulunur, halbuki bu veri tabanını poetik, estetik ve etik olarak geliştirmek istememiz de uygundur" (Manovich, 2011:219).

Üçüncü sentez tekrar edilendir. Tekrar edilen ise kendisini sadece çeşitlilik ve farklılaştıranda ifade edebildiğinden, üçüncü sentez fark'ın üretimine tabidir. Tekrar'ın fark'a dönüştüğü yer. Çağdaş kültürde bunu Pisters'ın ifadesiyle imgelemin bir tür «veri tabanını ileri sarması» halinde deneyimleriz. Üçüncü sentez yani gelecek zaman Hamlet'in zaman zıvanadan çıtı dediği zaman'dır. Patricia Pisters, Deleuze'ün zaman-imgeye örnek olarak ele aldığı Alain Resnais filmlerinde zaman-imgeye gömülü nöro-imgeyi incelerken bu filmlerde şimdiki, geçmiş ve gelecek zamanın savaşın ve ölümün ebedi dönüşü halinde gelecek zamanın birer boyutuna dönüştüğünü öne sürmektedir. Aslında Deleuze'ün Fark ve Tekrar 'da belirttiği gibi sadece şimdiki zaman vardır, gelecek zaman ve geçmiş zaman şimdiki zamanın boyutlarıdır ama üçüncü sentez yani gelecek zamanın perspektifinden şimdi ve geçmiş, gelecek zamanın boyutlarından fazlası değildir. Pisters'ın adı koyulmamış nöro-imge örnekleri olarak incelediği Resnais filmlerinde dönüşen boyut ölüm ve savaşla ilişkilidir ama bu aynı zamanda yaradılışın ve yeniden başlayışın boyutudur çünkü ebedi dönüşle içiçedir. Bu fimleri incelerken Pisters' in ortaya koyduğu zaman-imgenin belirli anlarda nöro-imgeye dönüştüğüdür. «Nöro-imgede gelecek zaman ebedi dönüşün serisel remikslenmiş tekrarlar yapmaya başladığ1 spekülatif an olur» (Pisters, 2012:145). Nöro-imge, veri tabanı mantığı özelliğinin yanı sıra ölüm, ölüm sonrası ve kozmik dünya'yla ilişkilidir. Nöro-imgeye zamanın üçüncü sentezi özelliğini veren dijital kültürün çevrimiçi internetle ilişkili veri tabanı mantığı, dijital imgenin ileri geri sarılabilme, remikslenebilme özelliğidir ama sadece bu değildir.

\section{Beyin Ekranlar ve Zihin Mimarileri}

Black Mirror (siyah ayna) dizisinde ekranlar, beyin ekranlar her yerdedir ve çok çeşitlidir. Her bölümde birbirinden farklı birçok ekran olmakla beraber sorunsallaştırılan belli ekranlar vardır. İmplantlar aracılığıyla insan beyninin arayüzü olarak çalışan ekranlardan karakterlerin varoluş ortamını oluşturan ekranlara (bkz: Beş Milyonluk Hak bölümünde bir tür arafta yaşayan karakterler), bu ekranların farklı teknik becerilerinin yanı sıra farklı mekansallıkları vardır ve birer makine rejiminin ögelerini oluştururlar. Ulusal Marş adlı ilk bölüm bir cep telefonunun yataktan düşmesi ve saatin çalmasıyla başlar. Hemen ardından sorunsallaştırılan beyin ekran, dev bir şantaj ekranına dönüşür. Bu bölüm, Bedenlenmiş Gösteri'nin teknodelirium'a eşlik eden makinesel krizine unutulmaz bir güzellemedir. Geçmiş zaman ve şimdiki zaman gelecek zamanın boyutlarına dönüşmüştür.

Black Mirror dizisinin ilk bölümünde duvarları aşarak yatak odalarımıza giren "düşman" "röntgenciye" dönüşmektedir. Düşman - röntgencinin kendisini de imha eden 
zaferini Birleşik Krallık ulusal marşı eşliğinde izleriz. Bu aynı zamanda Algı Lojistikleri 1.0 arzu makinesinin gözden kaybolma estetiğine veda edişimiz ve Alg1 Lojistikleri 2.0'1n her yerdeki (omnipresence) beyin ekranlarına ve vaat edilen Alg1 Lojistikleri 3.04 .0 vb. evrenlerine yelken açışımızdır. Panoptikon zıvanadan çıkmıştır.

Pisters nöro-imgenin en önemli özelliklerinden birinin nöro-imge sinemasında kahramanların gözünden değil zihninin içinden görmeye başlamamız olduğunu belirtmiştir. Ekran kavramsallaştırmamızın gözden beyne çekilmesi Black Mirror dizisindeki zihin mimarilerinin en önemli özelliklerinden biri, hatta en önemlisidir. Kubrick, Von Trİer, Resnais filmlerinde zaman-imgeden dolayımlanan bu geçiş Black Mirror dizisinde doğrudan hale gelmiş, hatta Black Museum bölümünün bir sahnesinde beyin fiziksel mekan olarak kullanılmıştır. Beynin ara yüzü olarak çalışan programlar ve bunların kullanımını sağlayan beyin implantlarıyla çağdaş beyin görüntüleme teknolojilerini çağrıştırır biçimde zihin, imgelem görüntülenmekte, simüle edilmekte, dijital teknolojideki geri sar ileri sar özelliği insan hafızasındaki görüntüler için kullanılmakta (Senin Tüm Geçmişin), implantlar aracılığıyla zihinsel simülasyonlara bağlanan karakterlerin ortaklaşa ve interaktif olarak deneyimlediği simülasyon evrenler sinemalaştırılmakta (San Junipero, Shriking Wipers), çocuğunu tehlikeden korumak isteyen aileler beyne takılan bir çiple, bir tür implantla çocuğun zihninden onun dahil olduğu dünyayı bir ekrandan izlemekte (Arkangel), sigorta şirketleri süregiden bir davanın gelişimi için olay yeri etrafındaki kişilerin hafıza kayıtlarındaki olay anı kaydını kullanabilmekte (Crocodile), suçu itiraf ettirmeye çalışan dedektif veya psikanalistin, hangisi olduğu son ana kadar belirsizdir, zanlı veya hastayı zihinsel simülasyonda geçmişe götürmesi ve itirafın alınması sağlanabilmekte, bitkisel hayattaki birinin zihnindeki müzik kaydedilip kapitalin yeniden üretimi için müzik piyasasina verilebilmektedir (Rachel, jack and ashley too).

Black Mirror dizisindeki zihin mimarilerin en önemli özelliği Pisters'ın nöro-imgede bulguladığı psikoza özgü zamansal mimaridir. Zamansal mimarinin Pisters tarafından nöroimgede bulgulanan en bariz iki özelliği Black Mirror dizisinde de bulgulanmıştır: Görünmezin makinesel rejiminin görünenin makinesel rejimininin yerini alışı ve hem dijital kültüre, hem zamanın üçüncü sentezine hem de şizoid beyne, psikozun zamansal mimarisine özgü veri tabanı mantığı.

Görünmezin makinesel rejimi zihnin başkalarına görülmeyen içsel gerçekliğidir ki patolojik şizofrenide bu tek gerçeklik halini alır, dolayısıyla patolojik şizofreniye, genel olarak psikozlara özgü zamansal zihin mimarisinin bir özelliğidir. Pisters incelediği filmlerde beyin-dünya diye ifade ettiği bu normalde göze görünmeyen dünyanın çağdaş sinemanın dolayısıyla nöro-imgenin karakteristiği haline geldiğini serimlemiştir. Bu durum görünmeyenin makinesel rejimi'nin görünenin makinesel rejimi'nin yerini alışıdır. Sinematografik anlatım açısından bu geçişin gerçekleşmesini çok büyük ölçüde kolaylaştıran dijital efektler olmuştur. Dijital efektlerin bugünki ölçüde gelişmesi ve yaygınlaşmasından önce sinematografik yaratıcılık gerektiren bu nitelik yeni teknolojiyle sıradanlaşmıştır ama daha önemlisi nöro-imge sinemasında dijital efektler kullanılmasa bile görünmezin makinesel rejiminin bir doğrudan anlatım biçimi olarak tercih edilir olmasıdır. Bu nedenle nöro-sinema estetiğinde öne çıkan özellikler; Pisters'ın serimlediği gibi «bir ressamın 
yaratabileceği görüntü kalitesi», şizoid yavaş çekimler ve geniş bir anlatım çeşitliliğinde dijital estetik ve bu dijital estetikle ekran anlayışımızın göz'den nöro-imgenin zihinsel dünyası'na kayışıdır.

Görünmezin makinesel rejiminin görünenin makinesel rejiminin yerini alışına nöroimge'ye zamanın üçüncü sentezindeki veri tabanı mantı̆̆ını veren özelliği eşlik etmektedir. $\mathrm{Bu}$ özellik de dijital kültüre ve zamanın üçüncü sentezine olduğu kadar psikozun zamansal mimarisine, şizoid beyne özgüdür. Kelebek Etkisi (The Butterfly Efect, Bress, E. \& Gruber, J. M. ,2004) filmini incelerken Pisters bunu flashback'ler kavramı eşliğinde açıklar. Klasik flashback'te şimdiki zaman belirlidir, sabittir ve flashback'ler bu şimdiki zamana dönerler, Kelebek Etkisi filminde ise bu şimdiki zaman belirli değildir. Dark (Baran bo Odar, Jantje Friese, 2017-günümüz) dizisinde nöro-imgenin bu özelliğinin tamamlanmış halini görürüz, Black Mirror dizisinde ise bunun en açı örneği özel bir bölüm olarak yayınlanan Bandersnatch bölümüdür. Zamanın Sentezleri bölümünde açıklandığı üzere gelecek zamana ait olan nöro-imge bu özelliğe sahiptir ve bunun sinematografik ifadesinde dijital teknolojinin sağladığı imgenin ileri geri sarılabilmesinin, remikslenebilmesinin büyük etkisi vardır. Bölümlerin tümünde zaman kurgusu izleyicinin araları tamamlayabileceği veya zihninde kendisinin kurgulayabileceği bir niteliktedir. Senin Tüm Geçmişin bölümünde zamanın bu özelliği dijital imgenin yeniden izlenebilme niteliğiyle vurgulanmıştır. Waldo Moment bölümünde çizgi karakter ile yaratıcısını zamanları özdeş değildir, White Christmas'ta sorgulayıcının zamanı ve olayın zamanı arasında klasik flashback türü bir ilişki kurmak imkansızdır. Hated in The Nation bölümünde de zaman blokları bildiğimiz zaman kurgusunun dışında, veri tabanı mantığıyla dizilmiştir. Striking Vibes ve San Junipero bölümlerinde gerçek zamana paralel simülasyon zamanları vardır. Black Museum bölümünde zamanın bu özelliği çok açıkça görülmektedir çünkü flashback'lerle öyküleri anlatılan karakterler oradadır, o karakterler açısından geçmiş, şimdi, gelecek içiçedir ve final bölümüyle gelecek zaman öngörümüz filmin geçmiş zamanına yerleştirilir.

Veri tabanı mantığı zihin mimarilerinde zihnin imgelerin, verilerin, metinlerin, ses ve görüntülerin aralarında yapısal bir ilişki olmadan biriktirildiği birer koleksiyona dönüşmesi haliyle de görülmektedir. Gayrişahsi bir hipertekst halinde zihin. Pisters karakterin zihnindeki dünyalar ve imgeler koleksiyonu aracılığıyla yolculuğa çıktığımız filmlerden bahseder bunun Black Mirror dizisindeki en tipik örneği White Bear bölümündeki kadın karakterin şizoid zihin mimarisidir. Kadın her sabah kolunda bir sargı beziyle uyanır, olduğu mekandaki ekranlarda belirli bir işaret, yerde intihar denemesinden kalmış gibi görünen saçılmış ilaçlar, bir erkeğe sarılmış kendi resmi ve bu resmin yanında bir çocuk resmi vardır. Resmi her görüşünde aynı çocuğun kadının zihnindeki imgesine gideriz, burada duygulanım bozulur, görüntü efektle bozularak verilir, kadının bedensel tavrı ise acı doludur. Ses-im görüntü-im devresi sinyal sesiyle tamamlanır. Kadın kim olduğunu hatırlayamaz ama her gün yeniden karşılaştığı bu ögeler aslında geçmişte yaşadığı bir öykünün yeniden düzenlenmiş veri tabanıdır. Bu aynı zamanda öznelliğin çağdaş dijital kültürde aşırı derecede çözülüşüdür ki öznelliğin aşırı derecede çözülmesi de zamanın üçüncü sentezine özgüdür. 
Şizoanaliz şizofreninin hem kapitalizme hem de kapitalizme direnmeye içkin olduğunu göstermiştir. Black Mirror dizisinde ise karakterlerin direnişlerinde Patricia Pisters'ın ifadesiyle «ahlaken aşkın veya güvenilir bir direniş noktası» olmadığını görürüz, aksine karakterler sürekli direnişin çoklu formlarını sistemden devşirmek ve keşfetmek zorundadır. Bunu yaparken bir yandan da kapitalizmin mantığına daha fazla kapılma ve ezilme riskinden kaçmak durumundadırlar. Halüsinasyonlar da onlara Delözyen Powers of false $^{3}$ bağlamında yol gösterebilir. Bilgisayar oyununa veya genel olarak dijital kültüre takıntı yine bir Powers of false olarak bu direnişe eklemlenebilir (Striking Vipers bölümünde evliliğin monotonluğuyla video oyununda deneyimlediği görünmezin makinesel rejimine ait tutku sayesinde başeder ve evliliğini kurtarır, alternatifi eşinin yaptığı gibi edimsel bir başka ilişki içine girmesidir). Güvenilir bir direniş noktası olmamasının en aşırı halini Metalhead bölümünde izleriz. Bölüm savaşlardaki el kameraları anlatısıyla çekilmiştir. Shut up and dance bölümünde olduğu gibi bu bölümde de düşman her yerdedir. Konumu kapatmak yetmez sürekli yeni direniş biçimleri keşfetmek gerekir. Filme distopik özelliğini veren karakterlerin bu keşiflerdeki yetersizliğidir. Rachel, Jack ve Ashley too bölümünde yapay zekanın karş1 üretimi kurtarıcıdır ama başka bir karşı üretim olan Waldo yaratıcısının elinden alınmıştır. Stratejiler karşı üretim yaratabilen nomadik stratejiler değildir. Kaçarak sorunu ertelemek, zarar vererek socius' u yeniden üretmek veya sorunun içinde boğulmak dişında yapabilecek bir şeyleri yoktur. Black Museum bölümündeki çok iyi hazırlanmış nomadik strateji socius'un yeniden üretilmesinin ötesine geçemez. Karşı üretim yaratabilen nomadik stratejiler yetersiz kalmaktadır. Ashley too'nun varlığını bir istisna olarak kaydetmek gerekir. İnsan tabanlı bir yazılımın karşı üretimi.

\section{Sonuç}

Black Mirror dizisinde zamansal mimarinin özellikleri distopyaya eşlik eden başl1 başına bir nomadik stratejidir ve nöro-imgenin özelliklerinden en önemlisi olarak bu çalışmada bulgulanmıştır. Beyin görüntüleme tekniklerinin, genel olarak nöroteknolojinin "terörle savaş" bahane edilerek davranışçı ve bilişsel denetim amacıyla üretimine karşı üretim. Dijital kültürün performans ekonomisinin merkezde olduğu kapitalist makinede insanı kendisini aşmaya kapitali yeniden üretme amacıyla zorlayan baskıcı denetçi üretimine karşı üretim.

Pisters nöro-imgede, genel olarak delirium sinemasında şizoanalitik ögelere bu kadar sık rastlanmasına teknomateryalist yönden iki açı ortaya koyarak bakmaktadır. Bunlardan birincisi sağ beyin-sol beyin işlevleriyle şizofreni arasındaki ilişkidir. Sağ beyin şimdiki zamanın beynidir. Sol beyin ise geçmiş zamanın ve gelecek zamanın. Hatırlayan ve projelendiren odur. Pisters algoritmalar, veri madenciliği vs ile sürekli önalımsal bir geleceği projelendiren, bir yandan da bütün bu dijital ögelerin konuşlandığı davranışsal denetimci rejimden mahremiyetini, zihinsel bütünlüğünü, öznel bütünlüğünü koruyarak kaçınmaya çalışan, bir yandan da geleceği projelendirmek için geçmişi ve bugünü birer veri tabanı gibi işleme tutmak zorunda bırakılan insan beyninin an'ı yaşamak isteyen sağ yarısının isyan

\footnotetext{
${ }^{3}$ Bkz: Deleuze, Cinema II: the time-image, 6. Bölüm.
} 
ettiğini öne sürmektedir. Delirium sinemasında psikozun bu kadar sık ifade edilmesinin bir nedeni budur.

İkinci açı plastite ile ilgilidir. Çağdaş nöro-bilim şizofreniyi sıradışı sinaps bağlantıları ve sıradışı plastite görülen beyin düzensizliği diye açıklamaktadır. Beyin plastitesi ise basitçe yeni becerilerle karşılaştığında beynimizin kendini yeniden düzenleme becerisidir. Sürekli ve tekrarlayan uyaranlarla karşılaştı̆̆ında bu düzenlemeler kuşaktan kuşağa aktarılır. Dijital kültür çağında sürekli yeni becerilerle karşılaşmak, performans ekonomisinin merkezde olduğu kapitalist makinenin şartları gereği bunları öğrenip geliştirmek zorunda olmakla yeni becerilerler edinip geliştirmekle başa çıkamamanın göstergesi olan psikoz arasında bir bağıntısallık vardır. Bu noktada Pisters'ın nörofelsefe açısından hatırlattığı önemli bir mesele kurgunun, tehlikeli ve ilüzyonvari olduğunda bile insan hayatı ve genel olarak insanlık tarihi için vazgeçilmez bir özellik olduğudur. Sinematografik nöro-imgede Delirium sineması ögelerinin sanat istenci aracılığıyla bir ifade biçimi olarak ortaya çıkışının nedeni budur.

Sonuç olarak diziye distopik niteliğini veren teknolojik gelişmeler değil, karakterlerin sorunlarla başa çıkmaya çalışırken nomadik stratejiler kurgulamakta, karşı üretimde yetersiz kalışıdır.

Black Mirror dizisi Pisters'ın nöro-imge kavramsallaştırmasının tüm özelliklerini taşımaktadır. Dahası Pisters'ın kavramsallaştırmasında nöro-imgeyi kuran dijital kültür ve nörolojideki gelişmeler bu çalışmanın materyali olan Black Mirror dizisinde içiçe geçmiştir, aralarındaki ayrımlar belirsizleşmiştir. Bunun nedeni dizinin işaret ettiği Alg1 Lojistikleri 3.0 olabilir, dizideki nöroloji, dijital kültür bütünleşmesi alg1 lojistiklerinde nöroteknolojinin baskın hale geldiği bir Algı Lojistikleri 3.0 çağını haber vermektedir. Ancak bu içiçe geçmenin üçüncü bir ögesi psikozdur. Dizi kurduğu distopyayla insanı yeni çağa zihnini rehabilite ederek ve nomadik stratejilerini geliştirerek hazırlanmaya çağırmaktadır.

\section{Kaynakça}

Baudrillard, J. (1995). The Gulf War did not take place. Indiana University Press.

Bergson, H. (1920). Mind-energy: Lectures and essays. H. Holt.

Bress, E. \& Gruber, M. J. (2004). Kelebek Etkisi. BenderSpink, FilmEngine, Katalyst Films. Kanada. ABD.

Brooker, C. (2011-günümüz). Black Mirror. Netflix, Birleşik Krallık.

Connolly, W. E. (2002). Neuropolitics: Thinking, culture, speed (Vol. 23). U of Minnesota Press.

Deleuze, G. \& McMuhan, M. (1998). The Brain Is the Screen: Interview with Gilles Deleuze on "The Time-Image". Discourse, 20(3), 47-55. Retrieved from www.jstor.org/stable/ 41389498

Deleuze, G. (2013). Cinema II: the time-image. Bloomsbury Publishing. 
Deleuze, G. (2014). Sinema I Hareket-İmge. İstanbul: Norgunk Yayınc1lık, 162.

Deleuze, G., \& Guattari, F. (2014). Anti-Ödipus, Kapitalizm ve Şizofreni 1, çev. Fahrettin Ege, Hakan Erdoğan ve Mustafa Yiğitalp, Ankara: Bilim ve Sosyalizm. İstanbul.

Deleuze, G. (2010). Nietzsche ve Felsefe, çev. Ferhat Taylan, Norgunk Yayıncılık,

Deleuze, G. (2017). Fark ve Tekrar, çev. Burcu Yalım ve Emre Koyuncu, 1.

Derrida, J. (1996). Archive fever: A Freudian impression. University of Chicago Press.

Hauptmann, D., \& Neidich, W. (2010). Cognitive Architecture: From Bio-Politics to NooPolitics; Architecture $\mathcal{E}$ Mind Inthe Age of Communication and Information.

Manovich, L. (2002). The language of new media. MIT press.

Neidich, W. (2009). Neuropower. Atlantica Magazine of Art and Thought, 48(49), 11965.

Palma, B. (2007). Redacted. HDNetFilms. Kanada. ABD.

Pisters, P. (2012). The neuro-image: A Deleuzian film-philosophy of digital screen culture. Stanford University Press.

Pontecorvo, G. (1966). La battaglia di Algeri. Casbah Film. İtalya.

Ronfeldt, D., \& Arquilla, J. (2018). The Continuing Promise of the Noösphere and Noöpolitik: Twenty Years After. Available at SSRN 3259425.

Schalk, R. (2017-günümüz). Dark (Dizi). ABD.

Virilio, P. (1989). War and cinema: The logistics of perception. Verso. 